\title{
Adenosine Kinase Inhibitor Design Based on Pharmacophore Modeling
}

\author{
Yuno Lee, Nagakumar Bharatham, Kavitha Bharatham, and Keun Woo Lee*
Deparment of Biochemistrv, Division of Applied Life Science, Enwrommental Biotechnologv National Core Research Center

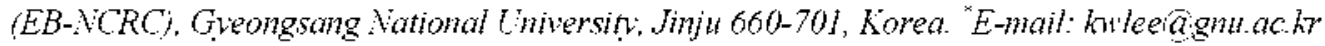 Received October 9,2006

\begin{abstract}
Adenosine kinase $(\mathrm{AK})$ is a ubiquitous intracellular enzyme. which catalyzes the phosphory lation of adenosine $(A D O)$ to adenosine monophosphate (AMP). AK inhibitors have therapeutic potential as analgesic and antiinflammatory agents. A chemical feature based pharmacophore model has been generated from known AK inhibitors (26 training set compounds) by HypoGen module implemented in CATALYST software. The top ranked hypothesis (Hypol) contained four features of two hydrogen-bond acceptors (HBA) and two hydrophobic aromatics (Z). Hypol was validated by 124 test set molecules with a correlation coefficient of 0.905 between experimental and estimated activity. It was also validated by CatScramble method. Thus, the Hypol was exploited for searching new lead compounds over 238.819 chenucal compounds in NCI database and then the selected compounds were screened based on restriction estimated activity and Lipinski 's rules to evaluate their drug-like properties. Finally we could obtain 72 new lead candidates and the two best compound structures from them were posted.
\end{abstract}

Key Words : Adenosine (ADO). Adenosine kinase (AK) inhibitors. Pharmacophore hypotheses. New lead search. Computer-aided dnig design

\section{Introduction}

Adenosine (ADO) is an extracellular signaling agent within the central and peripheral nervous system. ${ }^{1,2}$ It is a purine nucleoside released from the cells or formed extracellularly. and it diffuses to the cell membrane of surrounding cells and binds to adenosine receptors, ${ }^{2,3,4}$ During cellular stress, local intra- and extracellular concentrations of adenosine markedly increase. which is followed by the active transport of $\mathrm{ADO}$ out of the cell and subsequent activation of adenosine receptor subtypes. ${ }^{25}$ Activation of ADO receptors produces a variety of homeostatic inhibitory cellular events that contribute to anti-nociceptive and anti-inflammatory actions in wivo. ${ }^{6}$ Strong evidence suggests that this protective pathway is involved in pathological processes including neurodegeneration. seizures. ischemia. inflammation and pain. ${ }^{?}$

Adenosine kinase $(\mathrm{AK})$ is a ubiquitous intracellular enzyme. which catalyzes the phosphorylation of adenosine to adenosine monophosphate, and therefore is a key enzyme in the control of cellular concentrations of $\mathrm{ADO}{ }^{8}$ It rapidly phosphorylates $\mathrm{ADO}$, maintaining intracellular $\mathrm{ADO}$ concentrations at low levels. Since ADO uptake is driven by its concentration gradient. AK inhibition reduces the cellular uptake of $A D O$, thus potentiating the local concentration of $\mathrm{ADO}$ in the extracellular compartment as well as increasing the local concentration of $\mathrm{ADO}$ in the intracellular site. $\mathrm{AK}$ inhibitors. therefore, have therapentic potential as analgesic and anti-inflanmatory agents.

Until recently all of the reported $\mathrm{AK}$ inhibitors contained adenosine-like structural motif which resemble the natural substrate ADO. Nucleoside analogues in general are highly polar and rapidly metabolized. Our interest has been to discover non-nucleoside AK inhibitors free of mentioned side affects. The goal of this study is to construct a pharmacophore model based on common chemical features of existing AK inhibitors by using the HypoGen module implemented in CATALYST software. ${ }^{15}$ The pharmacophore modeling is a very effective method that allows scientists to gain valuable information of how ligands bind to the protein active site. ${ }^{11}$ It is expected to provide useful knowledge for developing new potentially active candidates targeting the AK. Hence, the best pharmacophore model was selected along with established protocols carefully and then it was validated by two methods. New compounds with similar features were retrieved from chemical database and they were screened based on their estimated activity and calculated drug-like properties.

\section{Methods}

Training Set Selection and Conformational Search. The most important process in pharmacophore model generation is the selection of training set compounds. Over the last few years, a number of AK inhibitors have been identified, and thus we have collected a set of 381 molecules whose $\mathrm{AK}$ inhibitory activity data were taken from the literature and generated a database by using MDL ISIS Base. ${ }^{12}$ Among these molecules. whose activities span a range of 5 orders of magnitude. training set selection was based on the fact that each order of magnitude is represented by at least three compounds. including the most active and inactive ones. It is extremely important to include the most active compounds as they contribute more to form the chemical feature based model. Conformations for all training set molecules were generated by an energy constraint of 20 $\mathrm{kcal} / \mathrm{mol}$. using Best Conformational Anctysis method and 
Table 1. Molecular structures of the 26 training set compounds

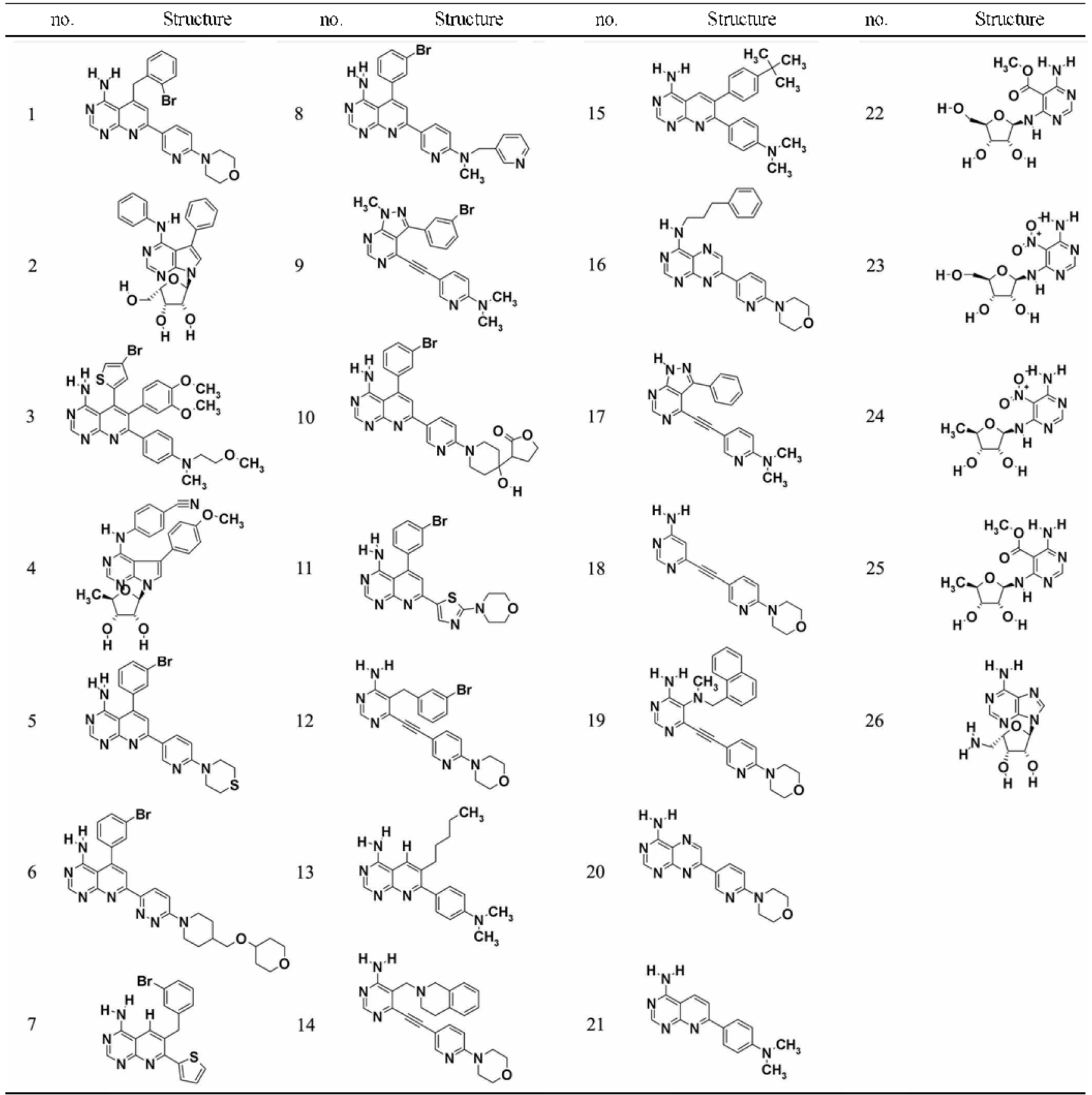

Poling Algorithm ${ }^{13}$ in CATALYST. A maxinum of 250 conformations of each molecule were generated to ensure maximum coverage of the conformational space. The training set comprising of 26 compounds representing structural diversity and wide coverage of activity range ( $\mathrm{IC}_{\text {sio }}$ ranging from 0.17 $\mathrm{nM}$ to $10000 \mathrm{nM}$ ) was used to generate pharmacophore hypotheses (Table 1). ${ }^{1+25}$ It comprises five scaffolds including nucleoside and non-nucleoside type AK inhibitors.

Generation of Pharmacophore Hypotheses with HypoGen. All training set compounds were structurally diverse and possessed certain common comparable inhibitory potencies. and chemical features. On the basis of the structural information from these known $\mathrm{AK}$ inhibitors a set of features crucial for activity were considered to represent a pharmacophore hypotheses. The HypoGen module in CATALYST was used to generate phamacophore hypotheses wherein it evaluates a collection of conformational models of molecules. and maps them to the selected chemical features (pharmacophore). The top ranked phamacophore is expected to identify the common binding features and the hypothetical orientation of the active compounds interacting with the target enzyme, protein, or receptor.

Validation of Pharmacophore Hypothesis. Validation of phannacophore hypothesis was done by two procedures ${ }^{26}$. 
test set method and CatSiramble method. The test set comprising of 124 compounds was collected from in-house database and confomers were generated in a similar way as that of training set compounds. Compounds which had only' similar assay were included in the test set and their activities were estimated using the best ranked pharmacophore. The statistical validation based on Fischer's randomization test was also performed using the CatScramble program. ${ }^{37}$ The goal of this type of validation is to check whether there is a strong correlation between the chemical structures and the biological activity and to generate pharmacophore hypotheses using a random reassignment of activity values among the molecules of the training set. In this statistical validation test we selected $95 \%$ confidence level and thus 19 spreadsheets were generated.

Database Screening. All the compounds with novel chemical structure and desired chemical features from NCI database consisting of 238.819 compounds were screened by the Hypol hypothesis. Database search was performed by the Best Flexible Search Databases of Spread Sheets method ${ }^{38}$

Drug-like Property Calculation. Lipinski's rule-of-five is a simple model to forecast the absorption and intestinal permeability of a compound ${ }^{2 y}$ According to the rule. compounds are considered likely to be well-absorbed when they possess less than 5 of $\log$. less than 500 of molecular weight. less than 5 of number of $\mathrm{H}$-bond donors. less than 10 of number $\mathrm{H}$-bond acceptors. and finally less than 10 of number of rotatable bonds. All these properties were calculated using Molinspiration online database. ${ }^{3 i j}$

\section{Results and Discussion}

Pharmacophore Hypothesis Generation. During a HypoGen run. CATALYST distinguishes between alternatives of thousands of models by applying cost analysis and by searching for the simplest set of chemical functions that correlate best with the observed activity. ${ }^{31}$ At the end of the run. it produces a set of 10 hypotheses using the data from the 26 training set compounds. Hypol is the most significant pharmacophore hypothesis in this study. characterized by the highest cost difference (73.824). lowest root-mean-square deviation (RMSD) (0.802). and the best correlation coefficient $(0.957)$. The fixed cost represents the simple model that fits all data perfectly while the null cost presumes that there is no relationship in the dataset. The fixed cost and null cost are 102.47. 185.614 respectively. The total cost describes each of the pharmacophore hypothesis with a value of 111.79 for Hypol which is much below the null cost and closer to the fixed cost.

A meaningful pharmacophore hypothesis may result when the difference between null cost and fixed cost is large. A value greater than 60 bits for a pharmacophore hypothesis is an excellent chance the model represents a true correlation and a value of $40-60$ bits may suggest that it has $75-90 \%$ probability of correlating the data. The cost values. correlation coefficients (r). RMSD, and pharmacophore features are listed in Table 2. From Table 2 we can see that all 10 hypotheses have conmon features of two lydrogen-bond acceptors (HBA) and two hydrophobic aromatics (Z) with the exception of only last hypothesis. The last hypothesis has different features with two HBAs. one $Z$ and one ring aromatic (RA). The Hypol contains four features of two HBAs and two Zs. Two-dimensional (2D) distances between all features in Hypol are shown in Figure 1.

Figure 2 shows that the Hypol aligned with the most

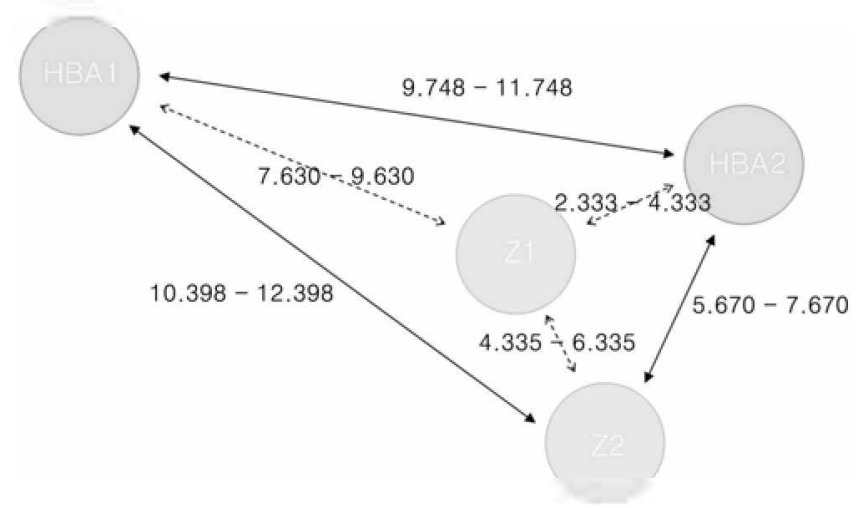

Figure 1. Two-dimensional representation of the top ranked hypothesis (Hypol). All distances are in $\AA$ unit.

Table 2. Intomation of statistical significance and predictive power presented in cost values for top lo hypotheses

\begin{tabular}{|c|c|c|c|c|c|c|}
\hline \multirow{2}{*}{ Hypo No. } & \multirow{2}{*}{ Features } & \multicolumn{4}{|c|}{ Training set } & \multirow{2}{*}{$\begin{array}{c}\text { Test set } \\
\text { correlation }(r)\end{array}$} \\
\hline & & Total cost & $\Delta \operatorname{Cost}$ & RMSD & Correlation(r) & \\
\hline 1 & AAZZ & 111.790 & 73.824 & 0.802 & 0.957 & 0.905 \\
\hline 2 & AAZZ & 113.998 & 71.616 & 0.941 & 0.939 & 0.824 \\
\hline 3 & AAZZ & 121.936 & 63.678 & 1.203 & 0.899 & 0.770 \\
\hline 4 & AAZZ & 122.843 & 62.771 & 1.250 & 0.891 & 0.674 \\
\hline 5 & AAZZ & 123.468 & 62.146 & 1.268 & 0.887 & 0.802 \\
\hline 6 & AAZZ & 123.597 & 62.017 & 1.271 & 0.887 & 0.741 \\
\hline 7 & AAZZ & 124.423 & 61.191 & 1.293 & 0.882 & 0.788 \\
\hline 8 & AAZZ & 124.594 & 61.02 & 1.285 & 0.884 & 0.779 \\
\hline 9 & AAZZ & 126.432 & 59.182 & 1.273 & 0.889 & 0.551 \\
\hline 10 & AAZR & 126.601 & 59.013 & 1.331 & 0.876 & 0.685 \\
\hline
\end{tabular}

Null cost of top-ten seore hypotheses is $185.61+$ bits. Fixed cost is 102.47 bits. Contiguration cost is 13.8914 bits. ${ }^{\circ}$ Abbreviation used for features: A, hydrogen-bond acceptor, Z. hydrophobic aromatic: R. ring aromatic. 
(a)

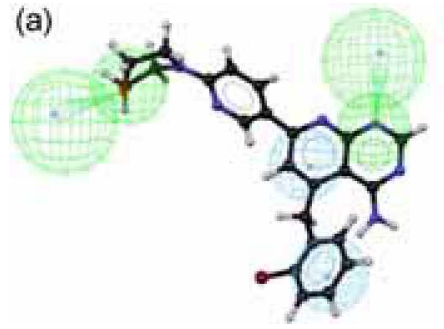

(b)

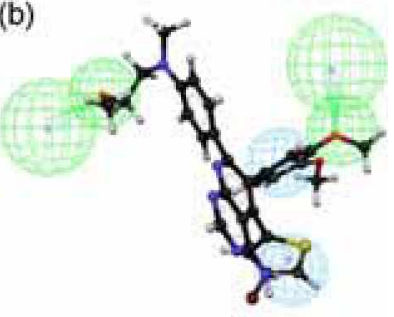

Figure 2. The Hypol mapping with training set compound l (a) and compound 3 (b). Pharmacophore features are color-coded: green for hydrogen-bond acceptor teature (HBA) and light blue for hy drophobic aromatic teature (Z).

active compound $\mathrm{I}\left(\mathrm{IC}_{50}=0.17 \mathrm{nM}\right)$ and compound $3\left(\mathrm{IC}_{50}=\right.$ $0.98 \mathrm{nM}$ ). among the training set molecules respectively. All compounds in this study were classified by their activity as highly active $\left(\mathrm{IC}_{50}<10 \mathrm{nM} .++\right)$. moderately active $(1000$ $\left.>\mathrm{IC}_{\mathrm{i} !} \geq 10 \mathrm{nM},++\right)$, and inactive $\left(\mathrm{IC}_{50} \geq 1000 \mathrm{nM}_{,}+\right)_{\text {. The }}$ estimated inhibitory activities of the 26 molecules in the training set were evaluated using Hypol and then compared to the experimental data in Table 3. Compounds of all

Table 3. Experinental biological activity and the estinated activity for the training set molecules based on the top ranked hypothesis

\begin{tabular}{|c|c|c|c|c|c|c|}
\hline & Experimental & Estimated & & & & Estimated \\
\hline Compd & $\begin{array}{c}\mathrm{IC}_{\mathrm{s0}} \\
(\mathrm{nM})\end{array}$ & $\begin{array}{l}\mathrm{IC}_{50} \\
(\mathrm{nM})\end{array}$ & Error $^{\Omega}$ & value & $\begin{array}{l}\text { Activity } \\
\text { scale }\end{array}$ & $\begin{array}{c}\text { activity } \\
\text { scale }\end{array}$ \\
\hline 1 & 0.17 & 0.19 & +1.1 & 8.26 & $+1+$ & $+1+$ \\
\hline 2 & 0.47 & 2.4 & +5 & 7.17 & ++ & ++ \\
\hline 3 & 0.98 & 0.9 & -1.1 & 7.59 & $+1+$ & $+1+$ \\
\hline 4 & 1 & 0.93 & -1.1 & 7.58 & $+1+$ & $+1+$ \\
\hline 5 & 1.3 & 5.4 & +4.1 & 6.81 & $+1+$ & $+1+$ \\
\hline 6 & 2.8 & 4.6 & +1.7 & 688 & $+1+$ & $+1+$ \\
\hline 7 & 3.8 & 9.3 & +2.5 & 6.58 & $+1+$ & $+1+$ \\
\hline 8 & 4.1 & 6.6 & +1.6 & 6.73 & $+1+$ & $+1+$ \\
\hline 9 & 7.5 & 18 & +2.4 & 6.30 & +++ & ++ \\
\hline 10 & 8.1 & 6.6 & -1.2 & 6.72 & +++ & +++ \\
\hline 11 & 12 & 5.2 & -2.3 & 6.83 & ++ & ++ \\
\hline 12 & 22 & 16 & -1.4 & 6.35 & ++ & ++ \\
\hline 13 & 30 & 160 & +5.3 & 5.34 & + & ++ \\
\hline 14 & 40 & 18 & -2.2 & 6.28 & ++ & ++ \\
\hline 15 & 63 & 110 & +1.7 & 5.52 & + & H \\
\hline 16 & 72 & 14 & -5.1 & 6.40 & + & + \\
\hline 17 & 100 & 21 & -4.8 & 6.23 & + & + \\
\hline 18 & 120 & 210 & +1.8 & 5.22 & + & + \\
\hline 19 & 250 & 78 & -3.2 & 5.65 & + & + \\
\hline 20 & 460 & 240 & -1.9 & 5.17 & + & + \\
\hline 21 & 770 & 340 & -2.3 & 5.02 & ++ & ++ \\
\hline 22 & 1000 & 1000 & +1 & 4.54 & + & + \\
\hline 23 & 2000 & 1600 & -1.3 & 4.36 & + & + \\
\hline 24 & 4000 & 3800 & -1.1 & 3.97 & + & + \\
\hline 25 & 6100 & 2600 & -2.3 & 4.13 & + & + \\
\hline 26 & 10000 & 18000 & -1.8 & 3.28 & + & + \\
\hline
\end{tabular}

"+ indicates that the estimated $\mathrm{IC}_{50}$ is higher than the experimental $\mathrm{IC}_{5 n}$; - indicates that the estimated IC $C_{S v}$ is lower than the experinental IC $C_{s i} ;$ a talue of 1 indicates that estimated $\mathrm{IC}_{5 \mathrm{v}}$ is equal to the experimental $\mathrm{IC}_{5 \%}$. ${ }^{5}$ Fit value indicates how well the teatures in the phammacophore overlap the chemical features in the molecule. "Activity scale:,$++- \mathrm{IC}_{5 n} \odot 10 \mathrm{nM}$ (highly active):,$-- 1000 \% \mathrm{IC}_{s,} \geq 10 \mathrm{nM}$ (moderately active); +. $\mathrm{IC}_{s,} \geq$ $1000 \mathrm{nM}$ (inactive).

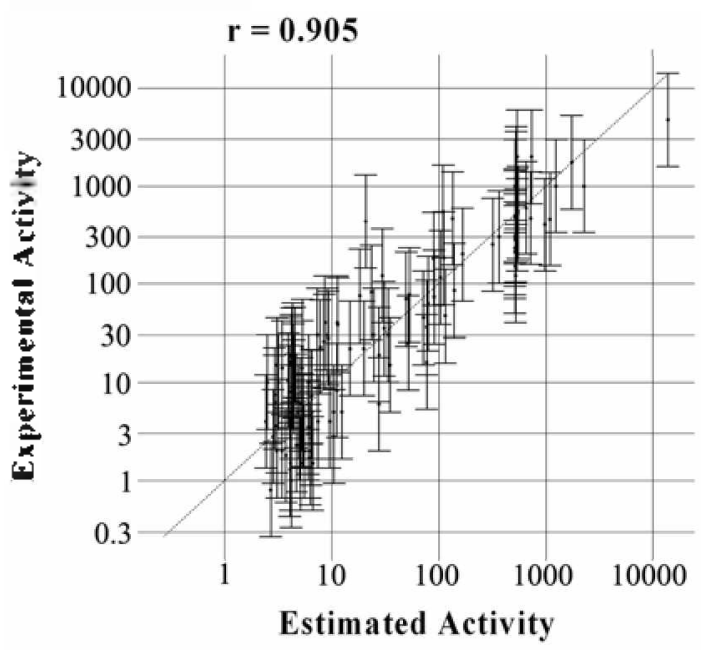

Figure 3. Correlation between experimental and estimated activity data over 124 test set compounds.

activity scale were predicted appropriately except for only two compounds. The compound 9 (highly active) was predicted to be moderately active and the compound 11 (moderately active) was predicted to be highly active

Validation of the Pharmacophore Model. The Hypol gave a correlation coefficient 0.905 between experimental and estimated activity for 124 test set molecules (Figure 3) and it was the best correlation among all 10 hypotheses (Table 2). As represented in Figure $4 \mathrm{a}$ and $4 \mathrm{~b}$, the mapping of Hypol onto highly active compounds in the test set were fit appropriately and had a estimated activity of $5 \mathrm{nM}$ (experimental $\mathrm{IC}_{50}=5 \mathrm{nM}$ ) and $9.1 \mathrm{nM}$ (experimental $\mathrm{IC}_{50}=$ $10 \mathrm{nM}$ ). respectively: The model was further validated by using CatScramble which generates random spreadsheets to create hypotheses using exactly the same features as used in generating the original phamacophore hypothesis. The results from the 19 spreadsheets are listed in Table 4 . The reasoning behind this procedure is that if the randomized data sets produced a hypothesis with a high correlation value than the original hypothesis. then the methodology of the pharmacophore generation is defective

The results of CatScramble clearly indicate that all values generated after randomization produced hy'potheses with no predictive value similar to that of original hypothesis. Out of 19 runs. only three trials had a correlation value around 0.7 . but the RMSD values were very high and the total cost values were almost equal to the null cost value. which is not (a)

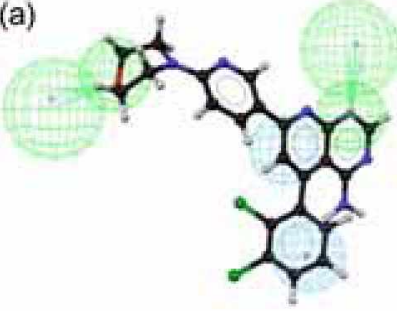

(b)

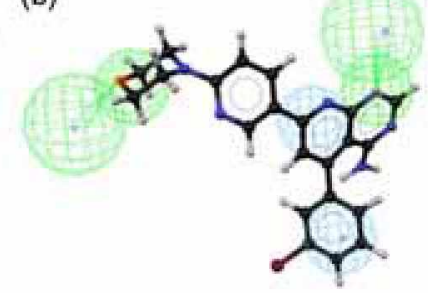

Figure 4. The Hypol mappug with two highly active compounds trom the test set. 
Table 4. Results from statistical validation using CatScramble implemented in CATALIST software

\begin{tabular}{|c|c|c|c|c|c|c|}
\hline Validation No. & Total cost & $\Delta \operatorname{Cost}$ & Fixed cost & RMSD & Correlation (I) & Contiguration cost \\
\hline \multicolumn{7}{|c|}{ Results for unscrambled } \\
\hline Hypol & 111.790 & 73.824 & 102.470 & 0.802 & 0.957 & 13.891 \\
\hline \multicolumn{7}{|c|}{ Results for scrambled } \\
\hline Lrial l & 156.787 & 56.820 & 99.967 & 2.073 & 0.638 & 11.388 \\
\hline Trial 2 & 171.106 & 71.240 & 99.866 & 2.335 & 0.528 & 11.288 \\
\hline Trial 3 & 159.052 & 56.206 & 102.846 & 2.078 & 0.655 & 14.267 \\
\hline Trial 4 & 151.878 & 46.109 & 105.769 & 1.868 & 0.734 & 17.191 \\
\hline Trial 5 & 163.257 & 60.886 & 102.371 & 2.163 & 0.617 & 13.792 \\
\hline Trial 6 & 170.052 & 68.621 & 101.431 & 2.289 & 0.554 & 12.852 \\
\hline Trial 7 & 182.615 & 88.544 & 94.071 & 2.584 & 0.400 & 5.492 \\
\hline Trial 8 & 149.323 & 50.973 & 98.350 & 1.946 & 0.709 & 9.771 \\
\hline Trial 9 & 180.660 & 78.335 & 102.325 & 2.454 & 0.450 & 13.747 \\
\hline Trial 10 & 174.147 & 71.153 & 102.994 & 2.314 & 0.545 & 14.415 \\
\hline Trial 11 & 151.442 & 47.106 & 104.336 & 1.899 & 0.723 & 15.757 \\
\hline Trial 12 & 166.759 & 68.206 & 98.553 & 2.287 & 0.554 & 9.974 \\
\hline Trial 13 & 161.561 & 60.668 & 100.893 & 2.134 & 0.633 & 12.314 \\
\hline Trial 14 & 166.107 & 63.009 & 103098 & 2.195 & 0.602 & 14.519 \\
\hline Trial 15 & 180.235 & 83.708 & 96.527 & 2.532 & 0.390 & 7.948 \\
\hline Trial 16 & 162.488 & 61.093 & 101.395 & 2.166 & 0.616 & 12.817 \\
\hline Trial 17 & 161.746 & 61.797 & 99.949 & 2.170 & 0.614 & 11.370 \\
\hline Trial 18 & 176.539 & 78.064 & 98.475 & 2.450 & 0.453 & 9.896 \\
\hline Trial 19 & 159.889 & 63.516 & 96.373 & 2.208 & 0.596 & 7.794 \\
\hline
\end{tabular}

Null cost of top-ten seore hypotheses is 185.614 bits. Fixed cost is 102.47 bits. Configuration cost is 13.8914 bits.

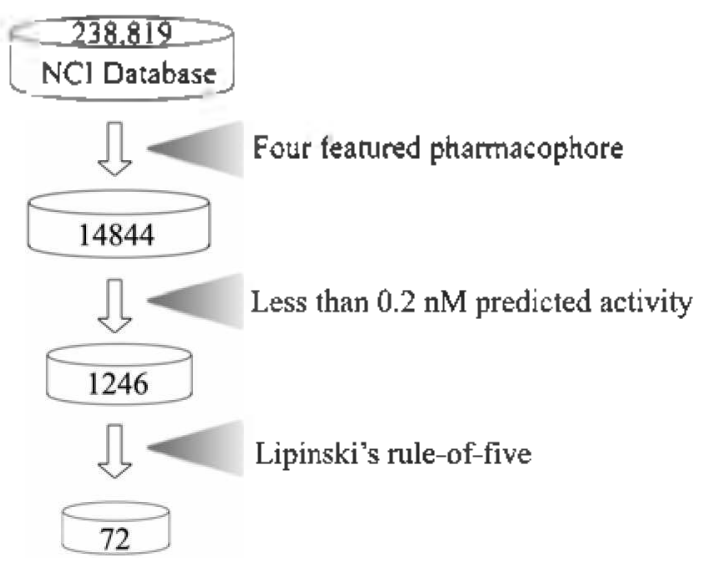

Figure 5. Flowchart of the screening procedure for new $\mathrm{AK}$ inlhibitor design.

desirable for a good hypothesis. Therefore. the statistical validation results strongly support that the Hypol is not generated by chance since its values are far more superior to those of the 19 random hypotheses generated. These validations provide confidence on our pharmacophore model and thus it had been used for the next step. new lead search.

Database Search. The validated four feature pharmacophore. Hypol was used to screen molecules with similar features from the $\mathrm{NCI} 2000$ database which contains 238.819 compounds. The 14,844 lead compounds were obtained from the first $3 \mathrm{D}$ query: Their activities were estimated and were screened based on various criteria as shown in flowchart (Figure 5). Upon restricting the minimum estimated activity to $0.2 \mathrm{nM}$ which is the activity threshold for the most active compounds. 1246 structures were left from the (a)
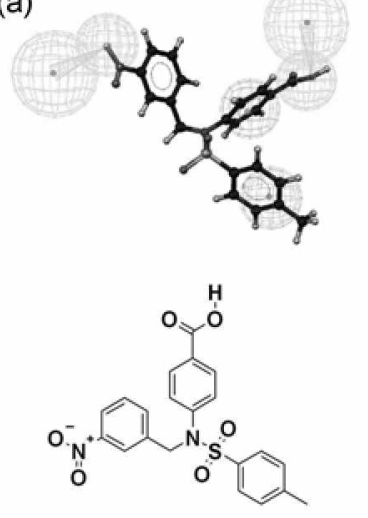

(b)

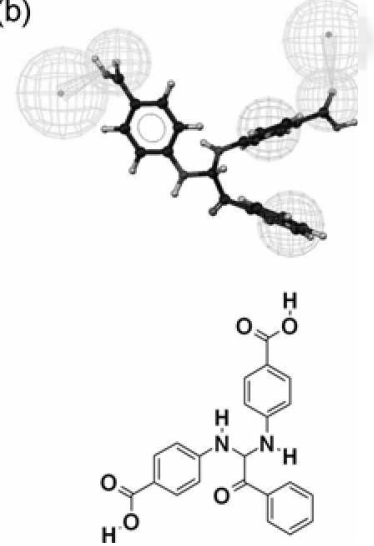

Figure 6. The Hypol mapping with new lead compound NCIO210803 (a) and NCIO109967 (b).

14.844 compounds. Properties of the each compound like $\mathrm{H}-$ bond donors. H-bond acceptors. number of rotatable bonds. LogP values can be calculated based upon the structure. Though there are no specific rules for an ideal drug candidate. Lipinski`s rule of five $(\operatorname{LogP}<5$, number of $\mathrm{H}-$ bond acceptors $<10$, number of $\mathrm{H}$-bond donors $<5$ ) give us a basic idea about the fundamental properties to be a drug. Thus. molecular weight and number of rotatable bonds were calculated in CATALYST spreadsheet and compounds which had molecular weight less than 500 and numbers of rotatable bonds less than 10 were only considered. Only 152 leads were obtained which were further screened for compounds having $\mathrm{H}$-bond acceptors less than 10 and $\mathrm{H}$-bond donors less than 5 using Molinspiration software. Ultimately 72 
lead compounds satisfied the Lipinski's rules indicating that they have ideal physiological properties. From the final 72 compounds. here we present only the two best candidate structures for new lead compounds. NCI0210803 and NCI0109967 (Figure 6). They showed an estimated activity' of $0.01 \mathrm{nM}$ and $0.012 \mathrm{nM}$. respectively and fitted well with the Hypol. Thus our pharmacophore model was able to retrieve few leads which had estimated inhibitory activity similar to most active compounds with acceptable calculated drug-like properties and therefore they could be recommended for further studies.

\section{Conclusion}

Our goal was to generate a predictive pharmacophore model that can be utilized to search 3D databases and screen them based on drug-like compounds to identify new nonnucleoside AK inhibitors. The 26 training set compounds were selected rationally and were used to generate pharmacophore hypothesis. The Hypol. generated for AK inhibitors is characterized by four features: two HBAs and two $\mathrm{Zs}$ which complement the active site nature with a high correlation coefficient of 0.957 . Our hypothesis was validated by the following two methods: first with a test set of 124 compounds; second by CatScramble method. The validated pharnacophore model was used for searching new lead compounds. Through the 3D query. 14,844 compounds were obtained from the 238.819 compounds of $\mathrm{NCI}$ database, and the number was reduced to 1246 when plysico-chenical properties were considered. The new lead candidate compounds were screened based on Lipinski's rule to have druglike properties and so finally we could obtain 72 compounds and two of them were posted in this article. Thus. our pharmacophore model was able to retrieve few leads which had estimated inhibitory activity similar to most active compounds with acceptable calculated drug-like properties and therefore they could be recommended for further studies.

Acknowledgment. Nagakumar Bharatham and Kavitha Bharatham were recipients of fellowships from the BK21 Programs and this work was supported by grants from the MOST/KOSEF for the Environmental Bioteclunology National Core Research Center (grant \#: R15-2003-012-02001-0) and for the Basic Research Program (grant \#: R01-2005-00010373-0).

\section{References}

1. Williams. M. Jarvis. M. Bichem. Pharmacol 2000. 59. 1173.

2. Ralevic. V.: Burnstock. G. Phamacol. Rew, 1998, 50.413.

3. Fredholn, B. B.: IJzerman. A. P. Jacobson, K. A.: Klotz, K. N.: Linden. J. Phamacol. Rev 2001. $53,527$.

4. Kim. S.: Jacobson. K. A.: Kim. H. S. Bull Korean Chem Soc. $2005,26,1503$

5. Williams. M: Burnstock. G. In Purinergic Approaches in Experintental Therapentics: Jacobson. K. A.. Jarvis. M. F.. Eds.: Wilev-liss: New York. 1997: p 3

6. Tarvis. M. F. Rev Analgesia 2003, 7,1

7. Kowaluk. E. A. Bhagwat S. S.: Jarvis, M. F. Cur Pham Des. $1998,4,403$
8. Arch, J. R. S.: Newsholme, E. A. Essaus Biochem. 1978. 1t, 82

9. Brake. A.: Schumacher. M.: Julius. D. Chent. Biol. 1996. 3. 229.

10. CATALIST +10. Accelrys. Inc: San Diego. CA. 2005. hittp: www accelrys.com

11. Samuel. T.: Jayashree, S.: Allister. J. M.: Jon. S. J. Chem. Inf. Hodel $2006,+6,728$.

12. The MDL ISIS base is available from MDL Information Systems Inc: : San Leandro. CA. http: www mdl.com

13. Snellie. A.: Teig. S.: Towbin. P. J. Conp. Chent 1995. J6. 171 .

14. Cowart. M.: Lee. C. H.: Gfesser. G. A.: Bayburt. E. K.: Bhagwat. S. S.; Stewart, A. O.: Yu, H.; Kohlhaas. K. L.; MeGaraughty, S: Wismer, C. T; Mikusa, J.: Zhu. C.; Alexander. K. M.: Jarvis. M. F.: Kowaluk. E. A. Biong Med. Chem. Lett 2001, 11.83.

15. Ugarkar. B. G.: Castellino. A. T.: DaRe T. S.: Ramirez-Weinhouse. M.: Kopcho. J. J.: Rosengren. S.: Erion. M. D. J. Hed. Chen. 2003. +6.4750

16. Perner. R. J.: Gu, Y. G:; Lee. C. H.; Bayburt. E. K.; McKie. J.; Alexander. K. M.; Kohlhaas, K. L.: Wismer, C. T.: Mikusa. J.; Jarvis, M. F.; Kowaluk. E. A.; Bhagwat. S. S. J. Hed. Chem. 2003. +6. 5249 .

17. Ugarkar. B. G: Castellino. A. J.: DaRe. J. M.: Kopcho. I. J.: Wiesner. J. B.: Schanzer. J. M.: Erion. M. D. J. Med. Chent. 2000. \$3. 2894.

18. Zheng. G. Z.: Lee, C. H.; Pratt, J. K.; Perner. R. J: Jiang, M. Q. Gomtsyan. A.: Matulenko, M. A.; Mao, Y.: Koenig. J. R.; Kim, K. $\mathrm{H}$ : Muchmore. S.: Yu, H.; Kohlhaas, K.: Alexander. K. M: MeGaraughty. S.: Chu. K. L.: Wismer. C. T.: Mikusa. J.: Tarvis. M. F.: Marsh. K.: Kowaluk. E. A.: Bhagwat. S. S.: Stewart. A. O. Biong. Med Chent Lett 2001. H. 2071.

19. Zheng. G. Z.: Mao, Y.: Lee, C. H.: Pratt. J. K.; Koenig, J. R.; Pener. R. J.: Cowart. M. D.: Gfesser, G. A.: McGaraughty, S.: Chu. K. L: Zhu, C: Yu. H.: Kohlhaas. K.: Alexander. K. M: Wismer, C. T.: Mikisa. J.; Jarvis. M. F.: Kowaluk, E. A.: Stewart. A. O. Biong Hed Chent Lett 2003. 13.3041

20. Perner. R. J: Lee. C. H.: Jiang. M.: Gu. Y. G.: Didomenico. S: Bayburt. E. K.: Alexander. K. M.: Kohlh aas. K. L.: Tarvis. M. F.: Kowaluk, E. L.: Bhagwat. S. S. Biorg. Med Chem. Lett. 2005, 15. 2803.

21. Gomtsyan. A.: Didomenico, S.; Lee, C. H.: Stewart. A. O: Bhagwat. S. S.: Kowaluk. E. A.: Jarvis. M. F. Biorg. Med Chent. Letf. 2004. 1H. 4165 .

22. Matulenko. M. A.: Lee. C. H.: Jiang. M.: Frey. R. R.: Cowart. M D.: Bayburt. E. K.: Didomenico, S. Gfesser. G. A.; Gomtsvan, A.; Zheng, G. Z; MoKie, J. A.; Stewart. A. O.: Yu. H; Kohlhaas. K. L.; Alexander, K. M.: McGaraughty, S.; Wismer. C. T:- Mikusa. J.: Marsh. K. C.: Snyder. R. D.: Diehl. M. S.: Kowaluk. E. A. Jarvis. M. F.: Bhagwat. S. S. Biorg. Med Chem. 2005. 13.3705.

23. Gontsyan. A.: Didomenico. S.: Lee. C. H.: Matulenko. M. A.: Kim. K.: Kowaluk. E. A:; Wismer. C. T.: Mikusa. J:; Yu, H: Kohlhas, K.: Jarvis. M. F.: Bhagwat, S. S. J. Med Chem 2002. 45. 3639 .

24. Lee. C. H.: Jiang. M.: Cowart. M.: Gfesser. G.: Perner. R.: Kim. K H.: Gu. Y. G: Williams. M.: Jarvis. M. F.: Kowaluk. E. A.: Stewart. A. O.: Bhagwat. S. S. J. Hed Chent 2001. H. 2133.

25. Lee. C. H; Daanen, J. F.: Jiang, M.; Yu. H; Kohlhaas, K. L.; Alexander. K.: Jarvis. M. F.: Kowaluk. E. L.: Bhagwat. S. S Biorg. 1fed. Chem. Lett. 2001. 11, 2419.

26. Bharatham. N.: Bharatham. K.: Lee. K. W. J. Mol Groph. Modet. 2006. 25. 813

27. Du. L. P.: Li. M. Y: Tsai. K. C.: You. Q. D.: Xia. L. Biochent Biophys. Res. Conmm 2005. 332,677.

28. Bharatham. N.: Bharatham. K.: Lee. K. W. Bull Korean Chent Soc. 2007. 28.200.

29. Lipinski. C. A.: Lombardo. F.: Domiay. B. W.: Freeney. P. I. Adh: Drug Deliv Rev: 1997. 23.3.

30. Tetko. I. V. Mini-Rev Med Chent 2003. 3. 809.

31. Sprague. P. In Perspectives in Drug Discoveny and Desigi: Anderson. P. S.. Kenvon. G. L.. Marshall. G. R., Muller. K.. Eds.; ESCOM: Leiden, 1995; Vol. 3. pp 1-20. 